\title{
MULTIDISCIPLINARY ANALYSIS OF THE VERNACULAR SETTLEMENTS IN USHGULI (UPPER SVANETI, GEORGIA)
}

\author{
G. Sousa ${ }^{1, *}$, G. Carlos $^{1}$, R. Florentino ${ }^{1}$, T. Bermudez ${ }^{1}$ \\ ${ }^{1}$ CI-ESG, Centro de Investigação, Escola Superior Gallaecia, Largo das Oliveiras, 4920-251 Vila Nova de Cerveira, Portugal - \\ (goretisousa, gilbertocarlos, ruiflorentino)@esg.pt, teresabermudez260@hotmail.com
}

\author{
Commission II - WG II/8
}

KEY WORDS: Upper Svaneti, Urban Morphology, Vernacular Architecture, History, Geomorphology

\begin{abstract}
:
Ushguli, located in the Upper Svaneti region (Georgia), represents the highest point of human occupation before the permanent snowed highlands that separate Georgia from Russia. The local inhabitants (Svan) are described as an aggressive community with warrior habits. Their history is one of permanent conflict. Most of the major empires of the ancient world (Persia, Greece, Rome and Byzantium) disputed this territory. In the Middle Ages, when natural conditions secured their isolation, the established feudal system preserved, until recent times, the warrior culture of the Svan through a judicial system based on blood feuds. The necessity to defend their territory from invaders, as well as the violent conflicts between families, influenced their settlement morphology, as well as their vernacular architecture. Four small settlements (Chvibiani, Zhibiani, Chazhashi and Murkmeli) constitute the Ushguli province, inscribed in the UNESCO World Heritage Site list since 1996. This paper aims to study the Ushgulli traditional urban morphology, which does not correspond to any classical urban element. The overlapping between private and public spaces and the inexistence of a standard concept of street or square are some of their peculiar features; some of which have an important influence on the organization of vernacular buildings. These buildings do not present a dominating facade or any other type of hierarchical composition towards the exterior. Under the scope of the Project 3D Past a multidisciplinary approach (Architecture, Urban Morphology and History) is used to better understand the original features of these peculiar settlements.
\end{abstract}

\section{INTRODUCTION}

Ushguli is a Svanetian province comprised of four small settlements (Chvibiani, Zhibiani, Chazhashi and Murkmeli) situated in the Caucasus mountains range, along the northern Georgian border. Ushguli represents the highest permanent settlements in Europe. The Caucasus mountain, reaching an altitude of $3000 \mathrm{~m}$, sometimes even $3500 \mathrm{~m}$, surrounds these settlements nestled along the Inguri valley and keeps them in almost complete isolation for most of the year.

Historically, this enduring isolation warranted additional protection to Upper Svaneti, converting this region to being the cultural strong-house of all Georgia. It also determined the preservation of peculiar cultural traces distinguished, in 1996, with the province`s inscription in the UNESCO World Heritage Site list, a well-deserved recognition for the high value of its Cultural Landscape. In 2016 it was selected as one of the case studies included in the 3DPast project - Living \& virtual visiting European World Heritage.

This project developed under the framework of the Creative Programme, from the European Commission, by Escola Superior Gallaecia, Portugal, Universitat Politènica de València and Università degli Studi di Firenze, Italy, aims to bring to attention the value of vernacular architecture, both in its tangible and intangible local know-how, the importance of preserving the fabric authenticity and integrity, especially in World Heritage sites.
Therefore, one of the aims of the project was to interconnect architecture, history and immaterial culture, in a genuine transdisciplinary approach. With this goal in mind, the urban morphology of the four settlements from Ushguli was analysed under a multidisciplinary approach.

Methodologically, this research started with an architectonic survey of the villages, aiming at characterizing the urban layout and the building culture, both materially and immaterially. With this characterization a second phase was delineated, in which the history and the territory was studied searching for the explanation for the peculiar urban layout of these villages and its architecture.

This paper addresses the historical and geographical background in which these settlements emerged and evolved, to better understand their urban morphology. It starts with a largescale approach in order to understand the territory and its interconnections with the settlement's natural site. Then the scale starts to decrease as the formation of the clusters and its distribution is analysed, to reduce once more for a final analysis of the cluster's morphology. In other words, the Ushguli territory and its history are analysed to set the background into which the urban morphological traces of the villages of Chvibiani, Zhibiani, Murkmeli and Chazhashi are analysed, finishing with a more detailed analysis of the urban layout of the last village.

Corresponding author 


\section{GEOGRAPHICAL BACKGROUND}

The landscape and climate of Upper Svaneti are closely influenced by the presence of the Caucasus mountain range. This proximity allows the distinction between different landscapes according to the proximity to the high mountain territory. Below $1800 \mathrm{~m}$ the climate is moderate, with a short but cold winter, with frequent blizzards, and a mild summer. At this altitude, the territory is covered by forests with fir, beech, oak, poplar, chestnut, birch, maple and pine trees. At a higher altitude (between 1800 and $3000 \mathrm{~m}$ ) the summer is very short and the winter is long and icy, and the forest gives place to the tundra and the alpine meadow. Higher still (above $3000 \mathrm{~m}$ ) there are only perennial glaciers and heavy snow and avalanches are quite common. The four settlements from Ushguli occupy a territory above $2000 \mathrm{~m}$, representing the highest point of human occupation before the permanent snowed highlands.

The region is rich in mineral resources such as alluvial gold, which was explored from ancient times until the XIXth century. An abundance that may explain, as discussed later, the attraction this remote territory exerted over all major empires of the ancient world. The existence of alluvial gold could also be the source of the connection between this region and the Greek myth of the Golden Fleece. In fact the Seoani used sheepskins in the traditional process of recovering the gold (Cappucci et al., 2015; Mardani, 2014).

Despite the region's richness in mineral resources, the land for agriculture is scarce. The Ushguli's settlements occupy a tundra and alpine meadow landscape, with poor soil for agriculture, but with abundant pastures.

Thus, the traditional economy was mainly dependent on forestry resources. The forest was the main source of wood, wild fruits and game. The wood was their main source of energy and hunting a traditional enterprise for the proud, aggressive and belligerent Svan man. But the forest also provided some protection against natural disasters, such as floods and avalanches (Kemkes, 2011; Mardani, 2014). These economic traces are constant until the present day.

\section{HISTORICAL BACKGROUND}

The first traces of human occupation of the Upper Svaneti's territory date back to the Bronze Age (Tserediani et al., 2018), when it was part of Colchis, a multitribal political entity that assured a considerable degree of autonomy to these clans. One of them was the Soani, which occupied Svaneti's territory (Pipia, 2013; Tuite, 2002), portrayed by the Greek historian, geographer and philosopher Strabo (63 B.C. - 24 A.C) as mighty warriors with the ability to summon a powerful army, reportedly of about 200.000 men.

The abundance of gold and copper attracted the interest of the major political players of Ancient History, such as the Achaemenids, Greeks, Romans, Persian and Byzantine (Berdzenishvili, 2016; Mikaberidze, 2007; Pataridze, 2017). This inclusion in the geopolitical strategies of the major empires brought development to the region, where several numismatic findings prove that Colchis was very active in commercial transactions with the Mediterranean and Asia Minor (Pataridze, 2017).
The territory of Upper Svaneti was one of the most important pieces in this geopolitical strategic game, due to the abovementioned mineral resources but also for its privileged situation in the commercial route that linked the Northern regions of the Caucasus and the Black Sea (Tevzadze, Vacheishvili, 2014).

But this prosperity was soon over with the consistent cooling of world climate that followed the Roman Climatic Optimum (250 BC- 400AC). The unusual warming of the North Atlantic Climate ensured the passage between Svaneti, the Black Sea and the North Caucasus region. After the V century, the passage for the Black Sea was permanently closed, and the communications with the northern neighbours were much more difficult. Therefore, the climatic changes left Svaneti in almost total isolation and devoid of its previous geostrategic interest.

Therefore, up until the arrival of the Medieval Climatic Optimum (950-1250), Svaneti was "as if in an impasse, where the approach road had crumbled, and the exit road went nowhere" (Tevzadze, Vacheishvili, 2014: 2). With the relatively warmer temperatures, although they were not as high as in the Roman period, the passages from Svaneti to the North where again reopened but not those that connected it with the Black Sea.

After the disintegration of Colchis, Svaneti had become an independent territory, governed by the local noble families. Later on, Svaneti was integrated into the Abkhazian Kingdom (780-1008) and, with the rest of the Abkhazian territory, into the Georgian Kingdom (1008). Upper Svaneti was, once more, a territory with geopolitical importance, this time for the Georgian dynasties (Berdzenishvili, 2016).

During this period Svaneti was simultaneously the most advanced defensive line and military outpost in the Georgian strategic motivations regarding the northern neighbours on the Caucasus (Tevzadze, Vacheishvili, 2014). The Svan maintained commercial relations with the Ossetian tribes, to the east, but these contacts also brought some hostility between them.

Between the XI and the XIII century, Upper Svaneti flourished with the so-called Georgian Golden Age, a period when most of the tower complexes and the orthodox churches that characterize the region were built.

But, after the XIII century, the medieval warm period was over and the passages were once more shut. Upper Svaneti was again an isolated territory and remained that way until the XIX century (Tevzadze, Vacheishvili, 2014). This isolation allowed the recovery of their political independence and kept them out of the Mongol invasion, thus becoming Georgia's cultural safehouse, but it also imposed a gradual decline process (Berdzenishvili, 2016; Tuite, 2002).

With natural conditions securing their isolation, the medieval feudal system was preserved, until recent times. This system is partially responsible for some of the main characteristics of the settlement's morphology and architecture. 


\section{USHGULLIS SETTLEMENTS URBAN MORPHOLOGY}

\subsection{Ushgulli`s settlements}

The Upper Svanetian defensive clusters were built in the Georgian Golden Age as a response to the above-mentioned strategic interest of the territory in the political ambitions of the Georgian kings, regarding the far northern region of the Caucasus.

Analysing the four settlements (Chvibiani, Zhibiani, Chazhashi and Murkmeli) according to their strategic position in the Caucasus geomorphological formations, the defensive intentions with which they occupy the territory become clear.

The villages are strategically placed on the crossings that connected the Upper Svanetian territory with the North of the Caucasus (Tevzadze, Vacheishvili, 2014), in perfect conformity with the political context on which they originated.

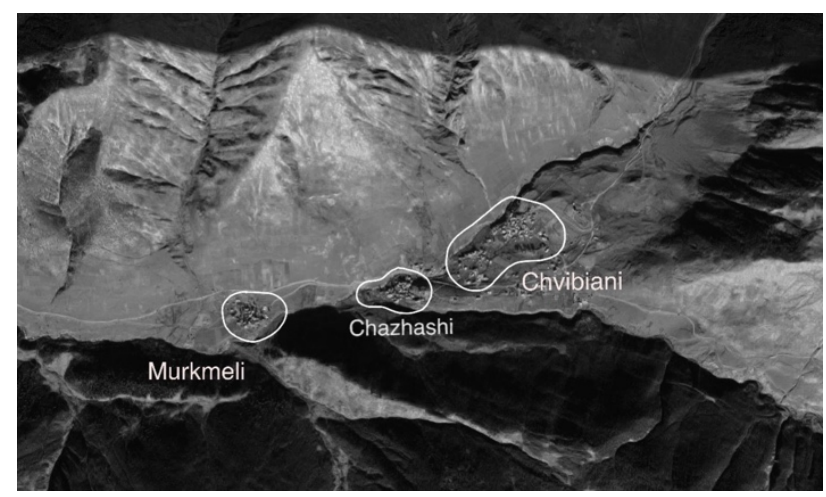

Figure 1. Ushguli`s Settlements strategic position, Ci-ESG, 2019.

Responding to these military goals the villages occupied the highland. All the Ushguli villages are situated above $2000 \mathrm{~m}$, when, as stated in the Geographical Background, the lower lands were more fitted for agriculture and forestry. The villages occupy the steep and difficult to access slopes of the mountain, choosing the rockier and unproductive lands to build their defensive clusters, in order to preserve the greater depth and fertile soil for agriculture.

The East/West orientation of the Inguri Valley sets the guidelines for the implantation of the villages. The four of them choose the North Slope in order to benefit from the southern sun. Around the villages, they set cultivated plots, traditionally barley-fields, as described in Freshfield (1896). Other crops could be found further down, around $1000 \mathrm{~m}$, such as wheat, flax, millet, etc. The south slopes of the valley are occupied by the forest. Kemkes (2011) signals the close connection between the limits of the Ushgulli settlements and the forest.

Therefore Ushgulli`s settlements implantation and morphology can be explained mainly by the necessity of defending the territory from invaders, but also by the violent conflicts between Svan feudal clans. These conflicts were common disputes in most feudal systems, but here, in Svaneti, the almost complete isolation that the region endured for centuries, warranted the survival of this medieval structure, developed somewhere between the VIII and the IX century, until recent times, through the conformation of a judicial system based on blood feuds, one of the main elements of the Svan cultural identity.
Military constraints are again the main explanation for the peculiar morphology of Ushgulli`s Villages. As explained by Mardani (2014) the identity of this urban landscape relies entirely on the defensive system, and the need to adapt to the natural features, and the social structure of the community.

Geology thwarts the building of a peripheral defensive wall, so the solution was to build "clusters of rustic castles" (Freshfield, 1896, p.183): a system that has proven to suit perfectly with the social structure of these feudal communities, given that each family built their own cluster.

Each cluster comprised a watchtower sometimes isolated, others attached to the house and a fence over their fields and pastures. This aggregation forced any newcomers to build their cluster far from the older ones (Mardani, 2014), thus maintaining the autonomy of each defensive unit and dispersing the clusters in the urban mesh. Therefore, the morphological layout of the villages does not correspond to any classical urban element.

The same isolation may explain some peculiar characteristics of the Svan feudal system, such as the appropriation, alongside the fief and the, also common, appropriation of public spaces by the feudal lords, as well as of the religious spaces by Svan noble families, with the construction of family chapels.

\subsection{Chazhashi`s urban morphology analysis}

Taking a closer look of Chazhashi's layout, one can observe how it does not present an articulated network, neither an evident hierarchic structure.

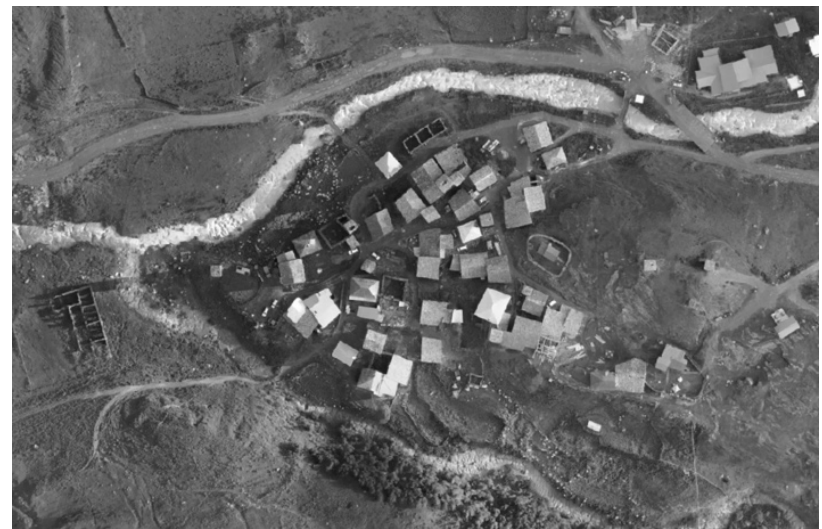

Figure 2. Point cloud model of Chazhashi, Upper Svaneti, after drone survey, Ci-ESG, 2019.

The overlapping between public and private space is constant, therefore conditioning the direct access to the buildings. This evidence is in accordance with the feudal system described above, where the lords appropriated the public and even the religious space. It also very clearly reveals their origin in isolated buildings, dwellings and towers, gradually evolving by aggregation and densification in an organic arrangement.

The buildings are isolated or grouped in smaller clusters, ranging from 2 to 5 units, with surrounding vacant space, exposing most of the facades of the buildings, except for the inner adjacent walls. Sections of fence walls usually bound most of the clusters into bigger units, segregating some of the building's residual peripheral areas from the circulation network, and thus reinforcing what can be interpreted as a very primitive urban block, although lacking the concept of the urban grid. 


\section{DISCUSSION}

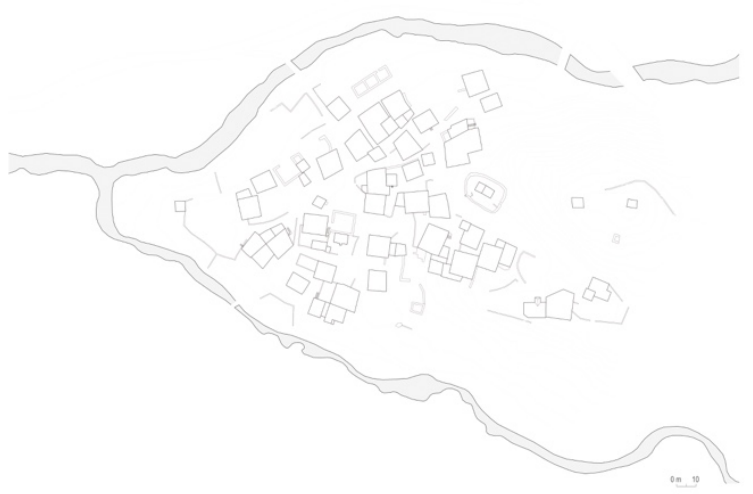

Figure 3. Chazhashi`s, Upper Svaneti, plan, Ci-ESG, 2019

Therefore, the canonical concept of Street, in its typical medieval channel shape, crossing the thick built density and conditioning the urban layout, does not exist in Chazhashi. The concept of Public Square is also absent, as there is no defined redoubt for the gathering of the community articulated with the communication network. The only exceptions are the two small temples and its walled enclosures.

This also justifies the fact that the buildings do not present a dominating facade or other types of composition hierarchy towards the exterior.

The 'public space' is rather the consequence of the interception of all the peripheral area of the isolated buildings and built clusters, comprising a network of different sized and configured spaces and passages. Another important feature of the circulation paths is its additional function as water drainage. Subject to heavy rain most of the year; the non-built space usually overlaps the natural ridgelines, an attempt to minimize the significant ground erosion. In some points, one can find transversal logs in the ground between buildings, forming steps.

It is only natural that the recent and intensive use of the car originates palpable conflicts with these traditional circulation spaces. The elevated detrition is increasing the soil permeability, compromising the stability of both the land and the buildings and creating areas of water accumulation.

Nevertheless, some distribution itineraries can be clearly identified in the village structure. Two surrounding itineraries bound the three land platforms of the mount, the connection passages after the three bridges and the permeable central space that crosses the platforms from the lowest West level to the East part of the settlement can be identified as the main circulation elements.

This characteristic layout is also observable in the remaining Ushgulli settlements. As a peculiarity, in Chazhashi one can mention the two isolated religious buildings dominated the highest area, located in the East area of the mount, where there is no presence of other dwellings. However, despite this singular feature and their social importance, their small dimension and the prominence of the several fortified towers clearly minimize the impact of these churches as village references.
This multidisciplinary approach, crossing different elements such as architecture, urban morphology, geography and history helped to explain the original features of the four settlements that belong to the province of Ushguli in Upper Svaneti, Georgia. The urban morphological analysis highlighted an organic arrangement derived from its origin in isolated buildings that evolved by aggregation and densification. Although an urban grid is not present, a primitive form of urban block can be drawn from the small clusters of buildings. Finally, it stresses the evident overlapping of public and private space, without any form of acknowledged concept of public space, such as streets or squares.

Overlapping these results with the geographical and historical background allowed the construction of some hypothesis concerning the development of this peculiar urban layout.

The first evidence is the strong connection of history and the climatic changes the territory endured; in such a way that one may say that they forge the history of this small province. The combination of the two explains the origin and later development of the four settlements. The position of these villages responds to strategic military and political interests, justified by the Georgian kingdom's medieval history, when Upper Svaneti was both the last defensive barrier, and the advanced post in their expansionist ambitions. But the main factor to take into consideration when deciding where to place a settlement was geomorphology, as the perfect coincidence of the villages with the crossing points to the North Caucasus seem to show. In fact, one can say that even the geopolitical interest of the province was due to this geomorphology.

When trying to explain the morphological characteristics of these villages' history is once again where to look for answers. And, this time, the explanation was the development of the feudal system, which led to the development of the defensive clusters, which by aggregation and densification formed the actual urban layout, thus explaining its organic plan. The perpetual violence between rival clans ensured that every family built their one defensive unit and the appropriation of public and religious spaces by the Svan noble families account for the overlapping of public and private space and the consequent inexistence of the former, at least in their conventional form. But the geography, with its rocky terrain and the scarcity of soil for agriculture, is, once more, noteworthy when analysing the dispersion of the defensive clusters inside the villages.

Finally, this multidisciplinary analysis showed a system of territory occupation and land use in perfect harmony with the natural surroundings and the socio-economic structure of the communities which occupy it.

\section{ACKNOWLEDGEMENTS}

This paper is the result of the research project 3D Past - "Living \& virtual visiting European World Heritage" [Grant Agreement Ref No570729-CREA-1-2016-1-PT-CULT-COOP1], which was co-funded by the European Union, under the programme Creative Europe (2016-2020). 


\section{REFERENCES}

Berdzenishvili, N., 2016. Svaneti - Ancient Historical and Geographical Province. Tourism Education Studies and Practice, 8(2), 39-43. doi.org/10.13187/tesp.2016.8.39

Cappucci, M., Pavliashvili, N., Zarrilli, L., 2015. New Trends in Mountain and Heritage Tourism: The Case of Upper Svaneti in the Context of Georgian Tourist Sector. Geojournal of Tourism and Geosites, 15(1), p. 65-78.

Freshfield, D., 1896: The exploration of the Caucasus. Edward Arnold, London.

Kemkes, R. J., 2011. Rural Household Livelihood Strategies, Forest Dependence and the Political Economy of Development in Upper Svaneti, Georgia. doi.org/10.1007/s00266-014-0379-2

Mardani, S. F., 2014. The Effect of Natural Landscape on Georgian Defensive Architecture (Case Studies: Mestia and Gori). Art and Civilization of the Orient, 2(4), p. 30-37.

Mikaberidze, A., 2007. Historical Dictionary of Georgia. In Historical Dictionaries of Europe, 50.

Pataridze, M., 2017. Political-Economic and EthnologicalReligious Aspects of Numismatic Material from Svaneti (5th c. $B C-18$ th c. $A D)$. St. Andrew the First-Called Georgian University of the Patriarchate of Georgia, Tbilisi.

Pipia, K., 2013. The Eastern policy of Rome and Colchis in The beginning of II Century A.D. The Caucasus And The World: International Scientific Journal, 15, p. 77-88.

Tevzadze, G., Vacheishvili, N., 2014. Project Svaneti. Svanetian Towers and Svanetian high art. History and hypothesis. Kadmos, 6, p. 362-368.

Tserediani, N., Tuite, K., Bukhrashvili, P., 2018. Women as Bread-Bakers and Ritual-Makers. In Sacred places, Emerging spaces: religious pluralism in the Post-Soviet Caucasus, p. 4669.

Tuite, K., 2002. Real and imagined feudalism in highland Georgia. Amirami, 7, p. 25-43. 